\title{
Racial Disparity in Potential Occupational Exposure to COVID-19
}

\author{
Abay Asfaw ${ }^{1}$ \\ Received: 3 May 2021 / Revised: 22 June 2021 / Accepted: 7 July 2021 / Published online: 5 August 2021 \\ (C) This is a U.S. government work and not under copyright protection in the U.S.; foreign copyright protection may apply 2021
}

\begin{abstract}
Background Nationwide, as of 20 June 2021, COVID-19 has claimed more than 599,000 lives and infected nearly 33 million people. Studies have shown that COVID-19 disproportionately affects some racial and ethnic minority groups. This study examined whether certain racial and ethnic groups were overrepresented in occupations with potentially high COVID-19 exposure risks, relative to their share in the total workforce. The study incorporates white collar workers, who to date have not gotten as much attention in terms of workers safety.

Methods Using the March and April 2020 Current Population Survey and O*Net data, this study examined whether certain racial and ethnic groups were overrepresented in occupations with potentially high risk of exposure to COVID-19 (exposure to disease and infection at work, inability to maintain physical distancing at work, and inability to work from home) relative to their share in the total workforce.

Results The results showed that Black workers were overrepresented in occupations with high potential risk of exposure to disease and infection at work and inability to maintain physical distancing at work. Hispanic workers were overrepresented in occupations where potential risk of inability to work from home was the highest.

Conclusion Occupation can be one of the risk factors for the current disproportionately high COVID-19 infection rates among Black and Hispanic workers. COVID-19-related prevention measures at high risk occupations, including providing adequate personal protective equipment, training, working space, and vaccinations, could help to reduce not only the spread of COVID-19 and infectious diseases but also their disproportionately high impact in certain minority racial and ethnic groups.
\end{abstract}

Keywords COVID-19 risk · Occupational risk · Racial disparity in occupational risk

\section{Background}

As of 20 June 2021, coronavirus disease (COVID-19) has claimed more than 599,000 lives and infected nearly 33 million people in the USA [1]. COVID-19 disproportionately affects certain racial and ethnic minority groups. Up to 7 March 2021 - the last date The COVID Racial Data Tracker stopped collecting racial data-COVID-19-related mortality rates were 178,172 , and 154 per 100,000 population for Blacks, American Indian or Alaska Natives, and Hispanics, respectively, compared to 124 and 95 per 100,000 population for Whites and Asians, respectively [2]. In Chicago, although Blacks constitute only $30 \%$ of the population, nearly $52 \%$ of

Abay Asfaw

AAsfaw@cdc.gov

1 Centers for Disease Control and Prevention (CDC), National Institute for Occupational Safety and Health (NIOSH), Economic Research and Support Office (ERSO), 395 E Street, SW,

Washington, DC 20201, USA
COVID-19-related deaths were among this group [3]. A study conducted by the Centers for Disease Control and Prevention (CDC) showed that the age-adjusted COVID-19-related hospitalization rates for non-Hispanic Black and Hispanic groups were approximately 178 and 161 per 100,000 , respectively, compared with 48 and 40 per 100,000 for Asian and White groups [3].

Factors such as a higher prevalence of pre-existing health conditions (diabetes, cardiovascular diseases, chronic lung diseases, and compromised immune systems), overcrowded living conditions, low socioeconomic status, and less access to quality health care services are mentioned in the literature as possible explanations for the current racial and ethnic inequalities in COVID-19-related mortality [4-11]. These factors alone may not adequately explain the current disparity in COVID-19 infection rates across different racial and ethnic groups. A CDC report showed that among those tested for COVID-19, the proportions who tested positive were $13.8 \%$ for non-Hispanic Blacks, $13.5 \%$ for Hispanics or Latinos, $7.2 \%$ for non-Hispanic Asians, and 7.0\% for non-Hispanic Whites [12]. 
Identifying and understanding factors that affect racial disparities in COVID-19 infection rates would help focus efforts to reduce the disproportional impact of the pandemic on certain groups. Work-related exposures are one of the major risk factors in the spread of infectious diseases [11, 13-15] such as COVID-19. For instance, Koh [16] indicated that "COVID19 is the first new occupational disease to be described in this decade." Moreover, focusing on factors beyond pre-existing health conditions and behavioral risk factors [17-19] sheds light on structural factors beyond individual behavior that impact the risk of COVID-19. The high racial disparities in COVID-19-related deaths in a younger population (aged $\leq 65$ years compared to aged $>65$ years) [20] also provides further justification for exploring work-related factors. This shift in focus matters because the workplace is a venue where interventions can take place. This also could help determine whether work-related hazards exacerbate the difference in COVID-19 infection rates among certain racial and ethnic groups.

The objective of this study was to examine whether certain racial and ethnic groups were overrepresented in occupations with potentially high COVID-19 exposure risks, relative to their share in the total workforce. Few studies have attempted to analyze the role of occupation in the current disparities in COVID19 infection rates [21-24]. Only Hawkins [25] has closely examined the role of occupation in the current racial and ethnic disparities in COVID-19 infection rates. This analysis contributes to and expands the literature in this area by extending Hawkins' study. I included additional risk factors, used employment data from the period in which the virus was clearly spreading in the USA (March and April 2020), measured racial occupational disparities relative to their share in the total workforce, and considered 83 three-digit occupations. I also extended the analysis beyond blue-collar workers and examined occupational risks for white collar workers, who to date have not gotten as much attention in terms of worker safety. Finding statistically significant differences in the proportion of racial and ethnic minority groups employed in occupations with potentially high risk of exposure to COVID-19 relative to their share in the total workforce would provide additional evidence that occupation can be one of the risk factors for the current racial and ethnic disparity in COVID19 infection rates. I hypothesized that Black and Hispanic workers were overrepresented in occupations with potentially high risk of exposure to COVID-19 during March and April 2020, when the virus was clearly spreading in the USA.

\section{Methods}

\section{Data Source}

I used average civilian employment data from March and April 2020 published by the Current Population Survey (CPS) of the Census Bureau (available at https://data.census. gov/mdat/\#/). CPS provides employment information by race, ethnicity, and occupation, as well as occupation information for main and secondary jobs. I picked March and April 2020 to reflect the employment situation once community transmission of COVID-19 had become established throughout the USA, with cases being reported in all 50 states and the District of Columbia [26]. I also considered both main and secondary jobs because a worker can be employed in two occupations with different potential risks of exposure to COVID-19. In the March and April 2020 CPS data, race information was not reported for around $10 \%$ of the total workforce. Workers with two jobs were counted twice in the analysis. This means that total employment based on the individual jobs would be higher than the total number of workers employed. During March and April 2020, an average of 1 million workers had two jobs.

In the CPS data, 375 different civilian occupations at different occupational classification levels with employment information are listed by occupation name. I used the 2018 US Bureau of Labor Statistics (BLS) Standard Occupational Classification (SOC) codes, available at https://www.bls. gov/soc/2018/home.htm, to match occupation names with occupation codes. Of note, the SOC is used to classify workers into different occupational categories for the purpose of collecting and disseminating data. The 2018 US SOC has 867 detailed (8-digit), 459 broad (6-digit), 98 minor (3-digit), and 23 major (2-digit) groups [27].

\section{Measurement of Variables}

\section{Race and Ethnicity}

I used the CPS race and ethnicity classifications of White (White), Black (Black), Asian (Asian), and Hispanic. Workers whose ethnicity was identified as Hispanic could be of any race. I did not consider other racial groups because their share of the total working population was small. For instance, the share of all workers identifying as two or more races among the total working population was $2.2 \%$ during the study period. The share of workers identifying as American Indian and Alaskan Native was less than $1.1 \%$. BLS does not report racial and ethnic information for occupation where the base is less than 50,000 workers [28]. In the March and April 2020 CPS data, information on race and ethnicity was not reported for over $10 \%$ of the total workforce.

\section{Overrepresentation}

My main objective was to examine whether different racial and ethnic groups were overrepresented in occupations with high potential risk of exposure to COVID-19 relative to their share in the total workforce. Overrepresentation was computed as follows. First, I calculated the share of each racial and 
ethnic group in each of the 83 three-digit level occupations. Second, I computed the share of each racial and ethnic group in the total workforce. Then, I assigned 1 to racial and ethnic group $i(i=1, \ldots, 4)$ if its share in occupation $j(j=1, \ldots, 83)$ was higher than its share in the total workforce (overrepresentation $=1$ ), and 0 otherwise (overrepresentation $=0$ ).

\section{Potential Exposure Risks to COVID-19}

I also used the BLS 2020-released O*Net 'work context' data available at https://www.onetcenter.org/database.html\# individual-files to estimate occupations' potential risks of exposure to COVID-19. The O*Net occupation data are updated every year, but not for all occupations and questions. In the 2020-released O*Net data, the period of updates ranged from 2002 to 2020 . Out of 57 'work context' questions included in the $\mathrm{O} * \mathrm{Net}$ data, I used 8 questions to estimate 3 types of potential risk of exposure to COVID-19 of different occupations: exposure to disease and infection at work, inability to maintain physical distancing at work, and inability to work from home. Note that not all risks of exposure to COVID-19 are accurately reflected in the O*Net risk indicators because, as mentioned, $\mathrm{O} * \mathrm{Net}$ data are not updated every year for all occupations. The current COVID-19 risk for some occupations can be very different from what is reported in the available $\mathrm{O} *$ Net data. For instance, the post-COVID-19 risk of infection for grocery store workers might also be lower than the pre-COVID-19 risk if control measures such as plexiglass cubbies and new store policies remain in place.

$\mathrm{O} *$ Net measures responses to the work context questions on a Likert scale of 1 to 5. O*Net also provides weighted standardized scores ranging from 0 to 100 for each question and each six-digit level occupations, based on different surveys and expert opinions (available at https://www.onetonline.org/help/online/scales). I used one $\mathrm{O} *$ Net question to measure the risk of exposure to disease and infection at work: "How often does this job require exposure to disease/infections?" I used two work-context questions to measure the risk of inability to maintain physical distancing at work; these asked about dealing with physically aggressive people and physical proximity at work. Note that these two questions do not specifically measure the ability of workers to maintain the recommended 6 foot distance from coworkers or customers. However, they measure the proximity of workers to other people at work. Finally, I used five work-context questions to measure the risk of inability to work from home. These asked about worker use of electronic mail; job requirement to work outside; exposure to minor burns, cuts, bites, etc.; need for wearing safety equipment at work; and job requirement of walking and running. See Table 1 for the details. Then, I aggregated the scores from six-digit to three-digit levels of occupations by giving equal weight to all six-digit level occupations. Finally, I matched the $\mathrm{O} *$ Net data to the three-digit level of occupations from the CPS data.

\section{Analysis}

From the total of 375 occupations in the CPS data, we matched 313 occupations to the 2018 BLS SOC codes by exact occupation name, and I matched the remaining $61 \mathrm{oc}-$ cupations manually. The full list of manually matched occupations is presented in online Appendix 1. One occupation, "office and administrative support occupations," was dropped because it is at the two-digit. During the study period (March and April 2020), this occupation employed less than $0.5 \%$ of the total workforce. As mentioned above, occupations in the CPS data are at different SOC levels; to be consistent, I aggregated the 374 occupations to 83 three-digit level occupations. Then, I matched the 83 three-digit level occupations from the CPS data to the O*Net data.

The dependent variables - potential risks of exposure to COVID-19-were standardized scores that ranged from 0 to 100 . First, I used 50 as a cut-off point; I considered occupations with standardized scores of $\geq 50$ as high risk and $<50$ as low risk. However, this cut-off point of 50 is arbitrary. Therefore, I also used all the standardized scores without making any cut-off point assumption. I compared the mean scores in occupations where different racial and ethnic groups were overrepresented with the overall mean scores using one-tailed $t$ test. For the regression analysis, I used a generalized linear model (GLM) because the dependent variables were restricted from 0 to 100 . GLM is a flexible generalization of non-linear least squares, which is optimal for these types of dependent variables. GLM requires choosing a link function and a distribution family. Based on a single-equation specification test, I used a GLM model with log link function and a negative binomial distribution. I used Stata software (version 14; StataCorp. 2015) to analyze the data.

\section{Results}

Overall, 83 three-digit level occupations were considered in the study (see online Appendix 2). In these occupations, during March and April 2020, on average 119 million workers with one job and 1 million workers with two jobs were employed. The shares of White, Black, Asian, and Hispanic workers in the total workforce were $79.3 \%, 11.2 \%, 5.8 \%$, and $18.0 \%$, respectively, during the study period. Among the 83 three-digit level occupations considered in this study, White, Black, Asian, and Hispanic workers were overrepresented in $47,31,30$, and 35 occupations relative to their shares in the total workforce. In the next sections, I present results that show whether the risks of exposure to COVID-19 were higher in occupations where certain racial and ethnic groups were overrepresented. 
Table 1 O*Net's 'work context' questions used to measure potential exposure risk to COVID-19

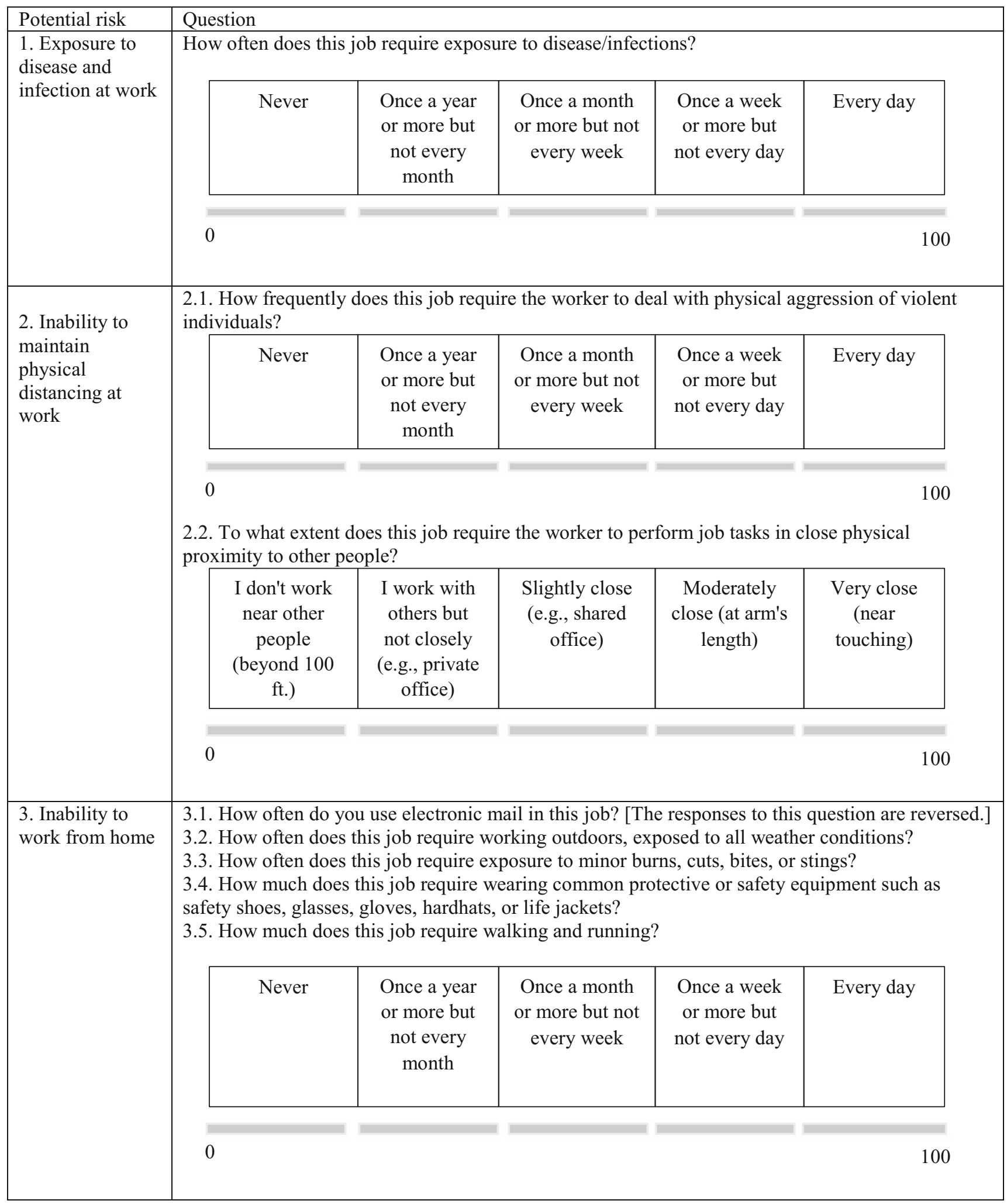




\section{Potential Risk of Exposure to Disease and Infection at Work}

The potential risk of exposure to disease and infection at work was approximated by the standardized score for exposure to disease and infection at work. The full results are presented in online Appendix 2. Workers in six occupations had a score of $\geq 50$ for potential exposure to disease and infection at work (Fig. 1). This means that around 9 million workers (7\% of the total workforce) were employed in occupations where the score for potential exposure to disease and infection at work was $\geq 50$. The next important question to be answered was whether specific racial and ethnic groups were overrepresented in these occupations relative to their share in the total workforce.

Figure 2 presents the share of different racial and ethnic groups in occupations with scores of $\geq 50$ for potential exposure to disease and infection at work, relative to their share in the total workforce. I also tested whether the share of each racial and ethnic group in these occupations was higher than their share in the total workforce. The results showed that Hispanic workers constituted $18.0 \%$ of the total workforce and $11.6 \%$ in the six occupations with scores of $\geq 50$ for potential risk of exposure to disease and infection at work, and the difference was statistically significant $(t$ test $=-$ $1.91 ; p=0.05)$. Asian workers constituted $5.8 \%$ of the total workforce, whereas their share in the six occupations was $4.6 \%$. This was $21.4 \%$ lower than their share in the total workforce. Similarly, White workers had a $1.6 \%$ lower share in the six occupations than their share in the total workforce. However, these differences were not statistically significant. In contrast, the share of Black workers in these high-risk occupations was $14.8 \%$, compared to $11.2 \%$ of their share in the total workforce, and the difference was statistically significant ( $t$ test $=1.74 ; p=0.07)$.

As indicated before, the cut-off point of 50 is arbitrary. To examine the validity of the above results, I examined the mean score for potential exposure to disease and infection at work by occupations in which different racial and ethnic groups were overrepresented (Fig. 3). The overall mean score for potential exposure to disease and infection at work was 18.8 for all 83 occupations considered in the study. In occupations where Black workers were overrepresented, the mean scores were 26.0, and the difference with the overall mean score was statistically significant $(t$ test $=1.76, p=0.04$ ). For all other racial and ethnic groups, the mean scores for potential exposure to disease and infection at work were not statistically different from the overall mean score.

GML results are presented in the second column of Table 2. In occupations where Black workers were overrepresented, the expected score for potential risk of exposure to disease and infection at work was 2.3 times higher than in occupations where Black workers were underrepresented (95\% confidence interval [CI] 1.33-4.14]. In occupations where other ethnic and racial groups were overrepresented, the coefficients were not statistically significant, again confirming the descriptive results.

\section{Potential Risk of Inability to Maintain Physical Distancing at Work}

The potential risk of inability to maintain physical distancing at work was approximated by the average scores of the two $\mathrm{O} *$ Net questions presented in Table 1 , and the full results are presented in online Appendix 2. Figure 4 shows the frequency distribution of the scores for potential risk of inability to
Fig. 1 Frequency distribution of scores for potential risk for exposure to disease and infection at work.

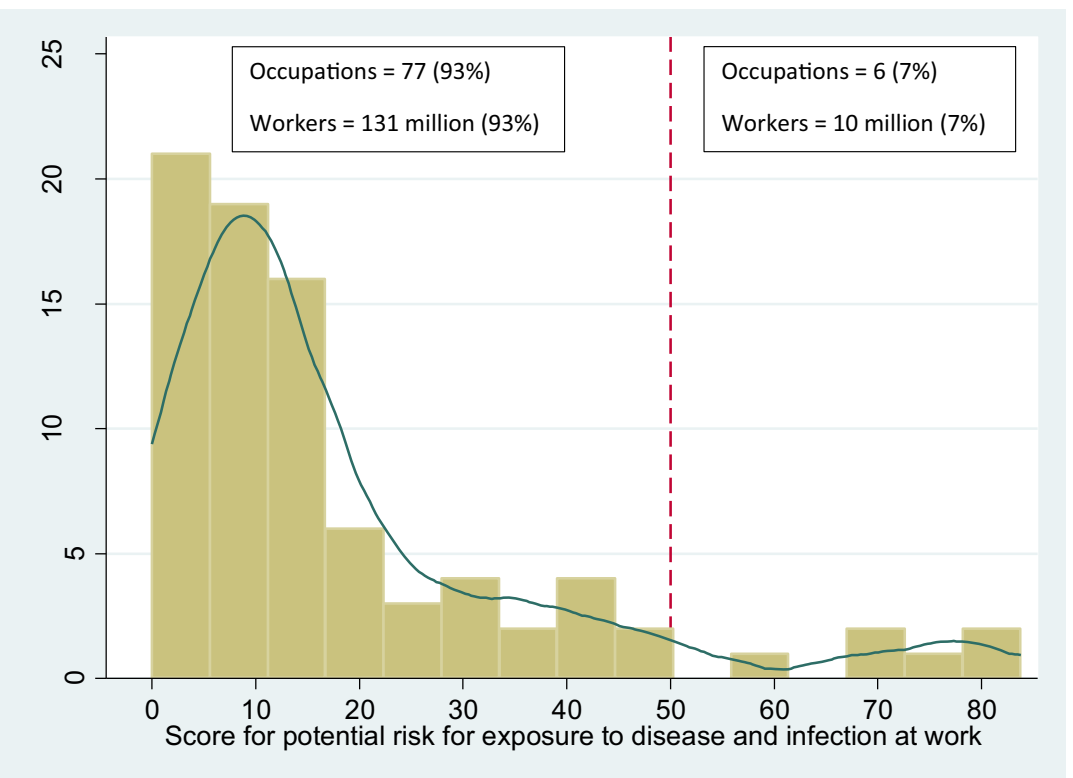


Fig. 2 Share of different racial and ethnic groups in occupations with a score of $\geq 50$ for potential risk of exposure to disease and infection at work, compared to their share in the total workforce. $* p<0.10$

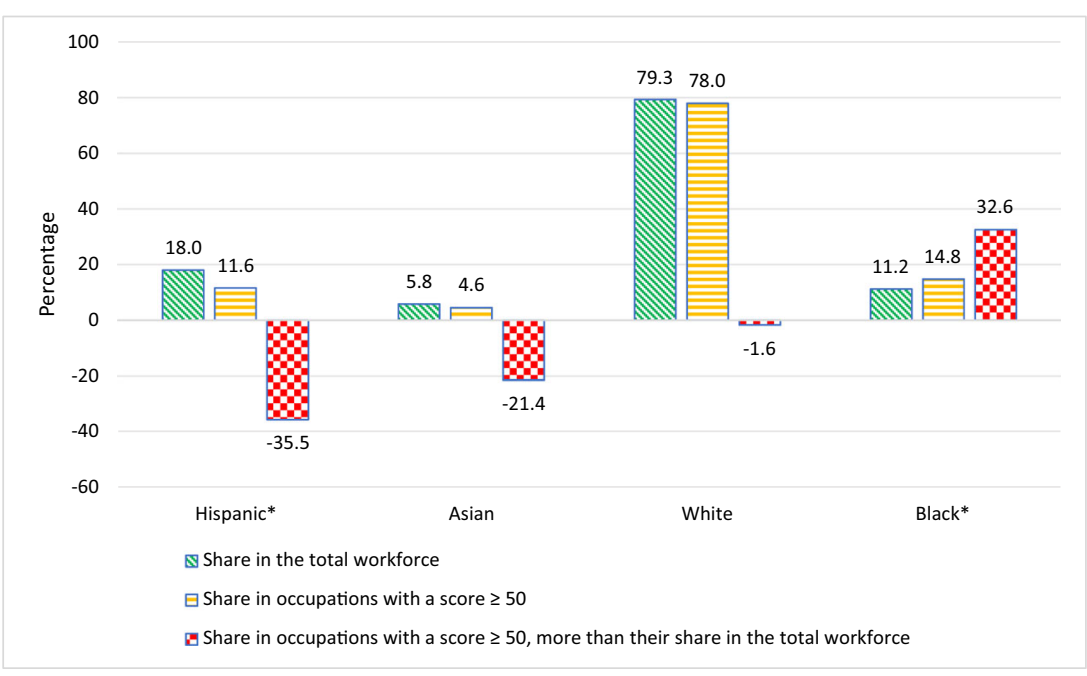

maintain physical distancing at work. Compared to potential exposure to disease or infection, more workers were exposed to the potential risk of inability to maintain physical distancing at work. Sixteen million workers were employed in 10 occupations with a score of $\geq 50$ for inability to maintain physical distancing at work.

Figure 5 presents the share of different racial and ethnic groups in these 10 occupations, relative to their share in the total workforce. Asian and Hispanic workers had $31.3 \%$ and $19.8 \%$ lower shares in these occupations than their share in the total workforce, and the differences were statistically significant (Asian: $t$ test $=-1.54 ; p<0.10$; and Hispanic: $t$ test $=-$ 2.35; $p<0.05$ ). In comparison, Black workers had a $53.8 \%$ higher share in these occupations than their share in the total workforce, and the difference was statistically significant ( $t$ test $=2.55 ; p<0.05$ ).

I also computed the mean score for potential exposure risk of inability to maintain physical distancing at work by occupation, in which different ethnic and racial groups were overrepresented relative to their share in the total workforce (Fig. 6). In occupations where Black workers were overrepresented, the mean score for potential risk of inability to maintain physical distancing at work was 41.7 compared to the overall mean score of 37.5, and the difference was statistically significant $(t$ test $=2.27 ; p=0.01$ ).

The GLM regression results are presented in the third column of Table 2. In occupations where Black workers were overrepresented relative to their share in the total workforce,
Fig. 3 Mean score for potential risk of exposure to disease and infection at work, by occupations in which different racial and ethnic workers were overrepresented relative to their shares in the total workforce. $* * * p=0.04$

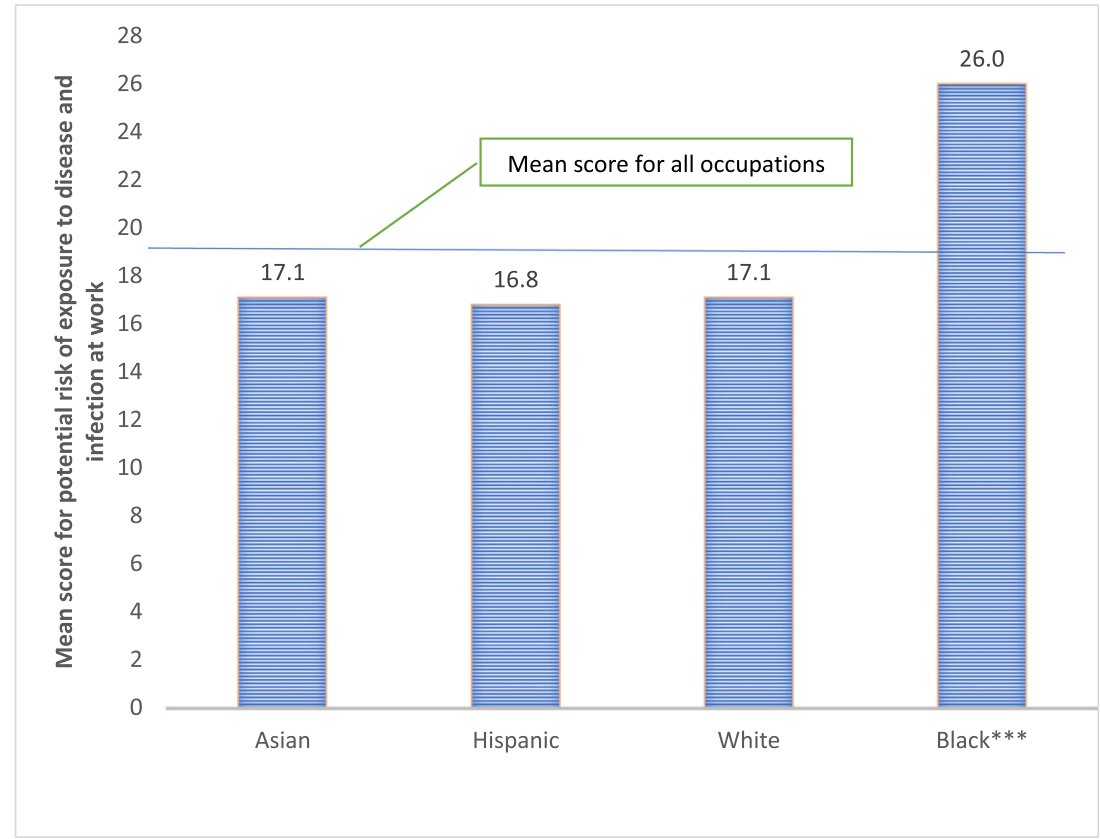


Table 2 Association between potential exposure to COVID-19 risks at work and overrepresentation of different racial and ethnic groups, relative to their share in the total workforce in different occupations: generalized linear model (GLM) results

\begin{tabular}{|c|c|c|c|c|c|c|}
\hline \multirow[t]{3}{*}{ Independent variables ${ }^{\dagger}$} & \multicolumn{6}{|c|}{ Dependent variables: ${ }^{*}$ Potential exposure to COVID-19 risks at work } \\
\hline & \multicolumn{2}{|c|}{ Exposure to disease and infection } & \multicolumn{2}{|c|}{ Inability to maintain physical distancing } & \multicolumn{2}{|c|}{ Inability to work from home } \\
\hline & IRR & $95 \% \mathrm{CI}$ & IRR & $95 \% \mathrm{CI}$ & IRR & $95 \% \mathrm{CI}$ \\
\hline White & 1.29 & $0.72-2.32$ & 1.02 & $0.86-1.06$ & 1.19 & $0.91-1.57$ \\
\hline Black & 2.34 & $1.33-4.14$ & 1.09 & $1.01-1.20$ & 1.24 & $0.93-1.64$ \\
\hline Asian & 0.97 & $0.55-1.73$ & 0.98 & $0.88-1.01$ & 0.74 & $0.59-0.93$ \\
\hline Hispanic & 0.68 & $0.45-1.03$ & 0.96 & $0.85-1.02$ & 1.63 & $1.32-1.99$ \\
\hline
\end{tabular}

$\dagger$ The independent variable for racial and ethnic group $i(I=1, \ldots, 4)=1$ if the share of racial and ethnic group $i$ in occupation $j(j=1, \ldots, 83)$ was higher than its share in the total workforce, and 0 otherwise

$\$$ The dependent variable was the score for potential exposure to disease and infection at work in occupation $j(j=1, \ldots, 83)$, which ranged from 0 to 100

Note. $C I=$ confidence interval, $I R R=$ incidence rate ratio

the potential exposure risk of inability to maintain physical distancing at work score was $9 \%$ higher than in occupations where Black workers were underrepresented (95\% CI 1.011.20). The coefficients of the variables for other ethnic and racial groups were not statistically significant.

\section{Potential Risk of Inability to Work from Home}

The potential risk of inability to work from home was approximated by using the average $\mathrm{O} *$ Net scores for five different questions presented in Table 1, and the full results are presented in online Appendix 2. Figure 7 shows the frequency distribution of the scores for potential risk of inability to work from home for the 83 occupations. Forty-two million workers were employed in 29 occupations with scores of $\geq 50$ for inability to work from home.

Figure 8 presents the share of different racial and ethnic groups in occupations with scores of $\geq 50$ for potential risk of inability to work from home, relative to their share in the total workforce. Compared to their share in the total workforce, there was no statistically significant difference in the share of White workers and Black workers employed in these occupations. Asian workers constituted $2.7 \%$ of workers in these occupations, half of their share in the total workforce $(t$ test $=-4.37 ; p<0.001)$. In comparison, Hispanic workers constituted about $25.5 \%$ of workers in these 29 occupations, although their share in the total workforce was only $18 \%$, and the difference was statistically significant $(t$ test $=3.66 ; p<$ $0.01)$.
Fig. 4 Frequency distribution of scores for potential risk of inability to maintain physical distancing at work

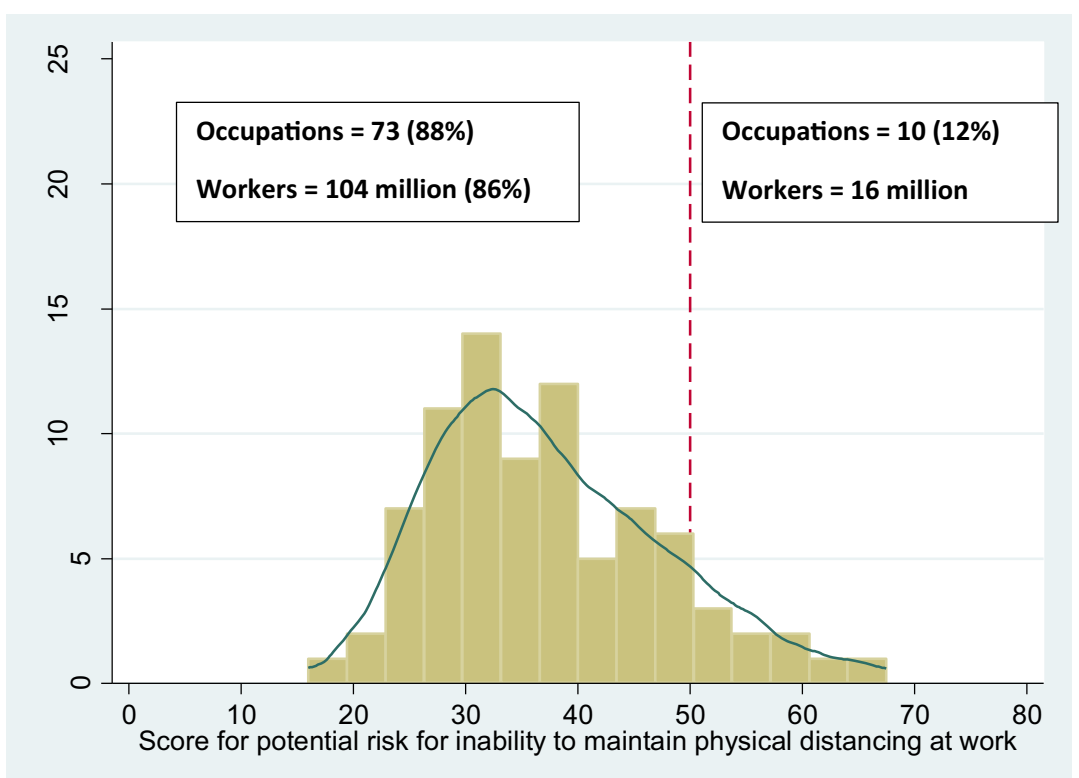


Fig. 5 Share of different racial and ethnic groups in occupations with a score of $\geq 50$ for potential risk of inability to maintain physical distancing at work, compared to their share in the total workforce. $* * p<0.05, * p<$ 0.10

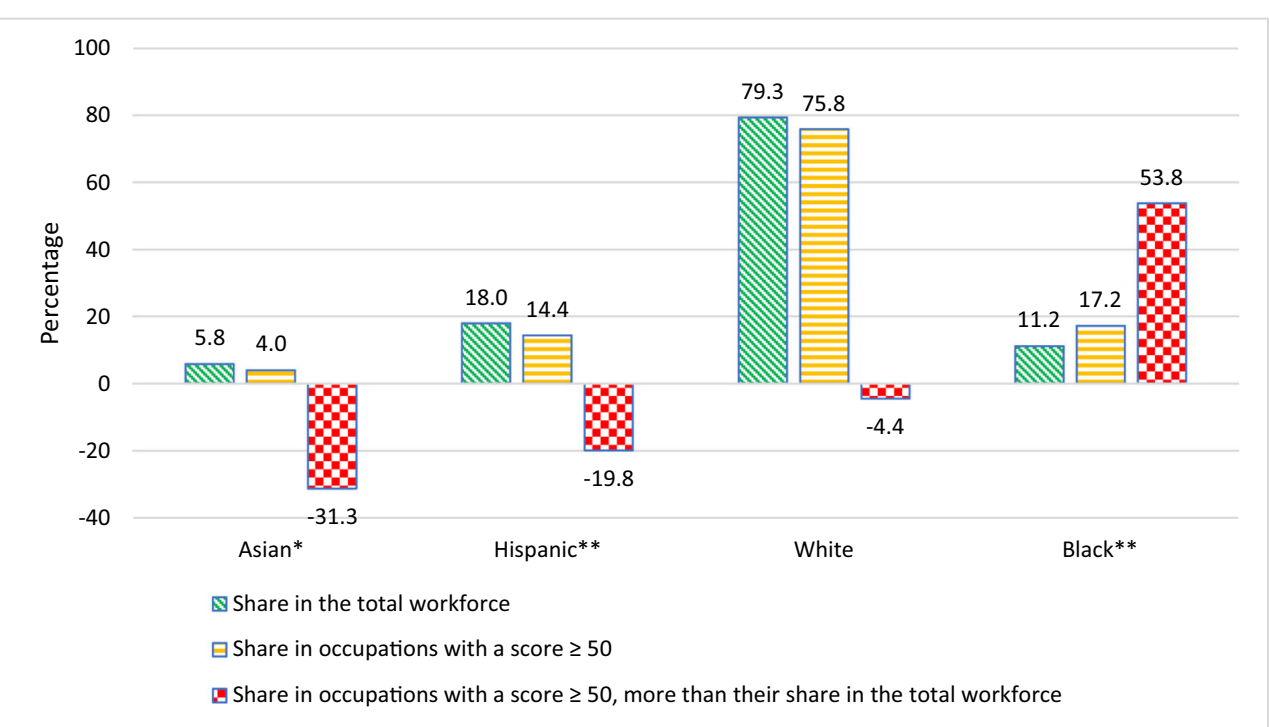

Figure 9 presents the mean score for potential risk of inability to work from home, in occupations where different racial and ethnic workers were over- and underrepresented. The overall mean score for potential risk of inability to work from home was 37.1. In occupations where Asian workers were overrepresented, relative to their shares in the total workforce, the mean score for potential risk of inability to work from home was $23.8 \%$ lower than the overall mean score, and the difference was statistically significant $(t$ test $=2.84 ; p<$ $0.01)$. In occupations where Black workers were overrepresented, the mean score was $14.7 \%$ higher than the overall mean score, and the difference was statistically significant $(t$ test $=1.81 ; p=0.04$ ). In occupations where Hispanic workers were overrepresented, the mean score was $30.9 \%$ higher than the overall mean score, and the difference was statistically significant $(t$ test $=3.93 ; p<0.01)$.

The GLM results presented in the last column of Table 2 confirmed the descriptive results. In occupations where Asian workers were overrepresented, the expected score for potential risk of inability to maintain physical distancing was $26 \%$ lower (95\% CI 0.59-0.93) than in occupations where Asian workers were underrepresented. In occupations where Hispanic workers were overrepresented, the expected score for potential risk of inability to work from home was $63 \%$ higher (95\% CI 1.32-1.99) than in occupations where Hispanic workers were underrepresented.
Fig. 6 Mean score for potential exposure risk for inability to maintain physical distancing at work, by occupations in which different racial and ethnic workers were overrepresented relative to their shares in the total workforce. $* * * p<0.01$

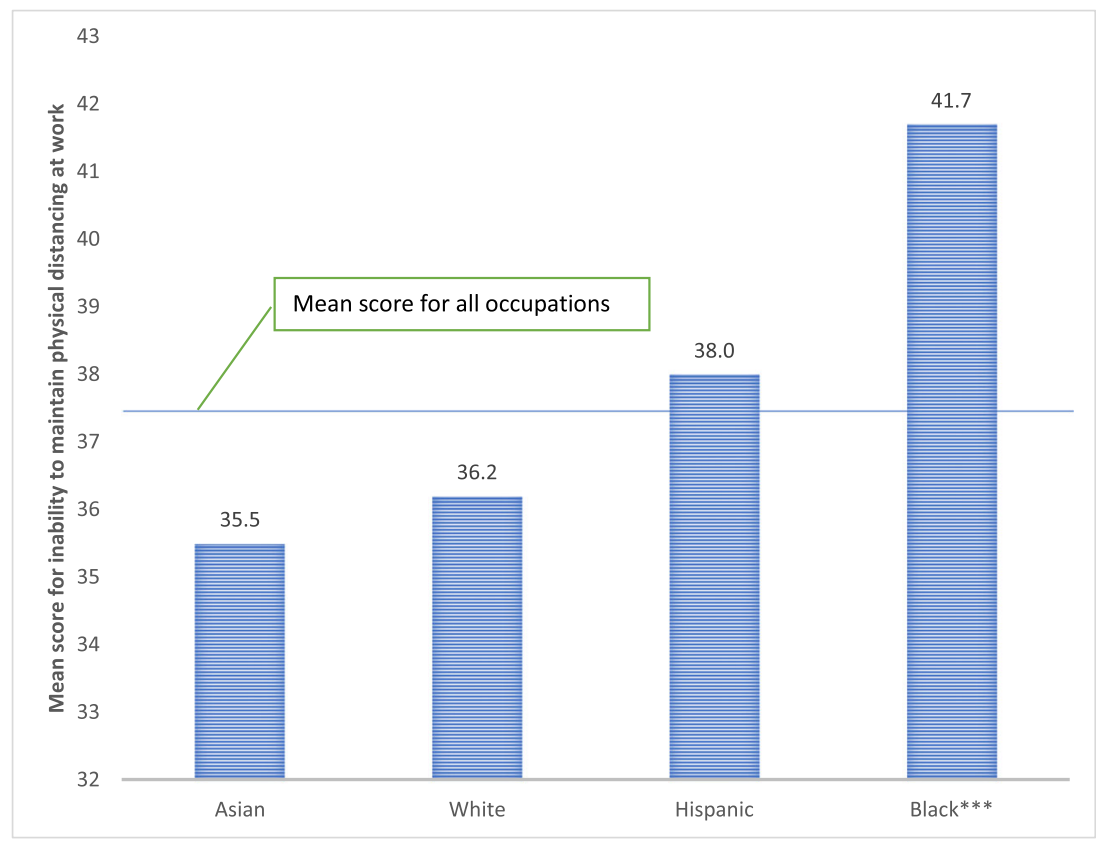


Fig. 7 Frequency distribution of scores for potential risk for inability to work from home

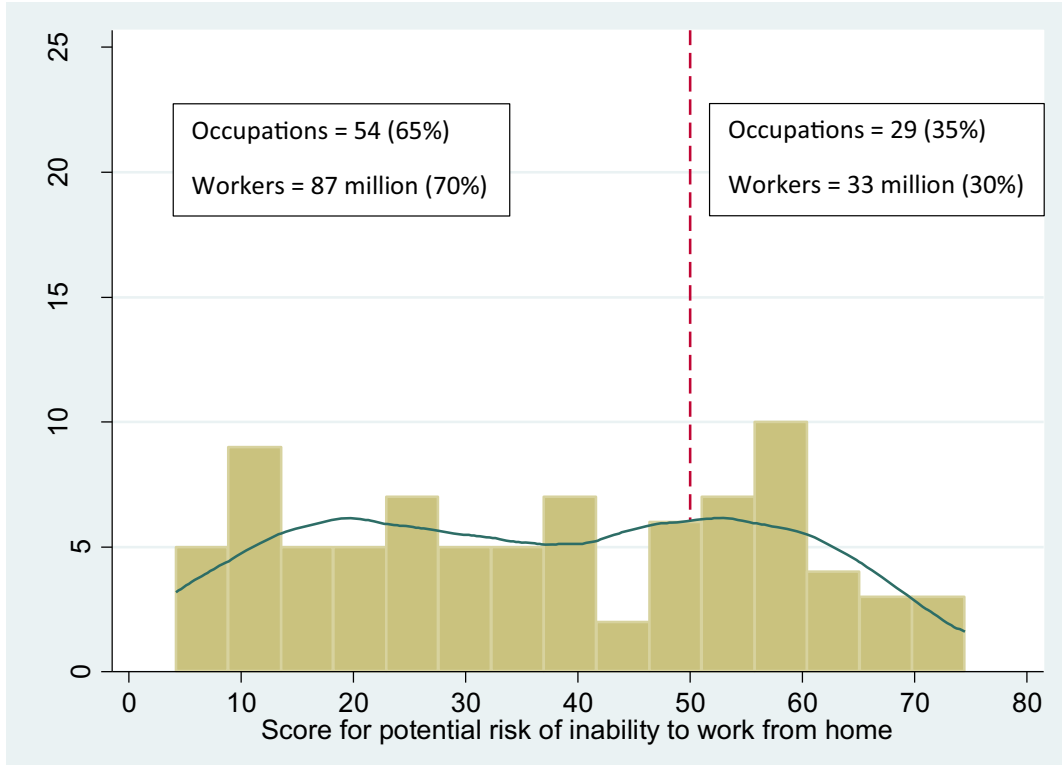

\section{Discussion}

The literature shows significant racial and ethnic disparities in the rate of COVID-19 cases, hospitalizations, and mortality [3, 23, 29-31]. Although differences in pre-existing health conditions and access to health care services explain some of the racial disparities in COVID-19 hospitalization and mortality rates, additional factors might be contributing to the current high racial and ethnic disparity in COVID-19 infection rates. Understanding the root causes of this disparity would help focus efforts to reduce the transmission of the virus and mitigate its disproportionate impact on disadvantaged groups.

Occupation can contribute to the disproportionately high exposure of certain racial and ethnic groups to COVID-19 through at least three different ways. First, workers in certain occupations are often exposed to infection or disease in their workplaces. The findings of this study showed scores of $\geq 50$ for exposure to disease or infection at work in these three-digit level occupations: occupational therapy and physical therapy assistants and aides; healthcare diagnosis or treatment practitioners; health technologists and technicians; other healthcare support workers; funeral service workers; and supervisors of protective service workers. These are expected results as most of the healthcare workers are occupationally exposed to different types of infectious diseases while performing their duties [32]. During March and April 2020, 9 million workers were employed in the above six occupations. This number is lower than the 14.4 million workers (10\% of the total workforce) reported by Baker et al. [15]. This could be partly because of methodological differences in measuring this risk. Also note that in the March and April 2020 CPS data, information on race and ethnicity was not reported for more than
Fig. 8 Share of different racial and ethnic groups in occupations with a score of $\geq 50$ for potential risk for inability to work from home, compared to their share in the total workforce. $* * * p<0.01$

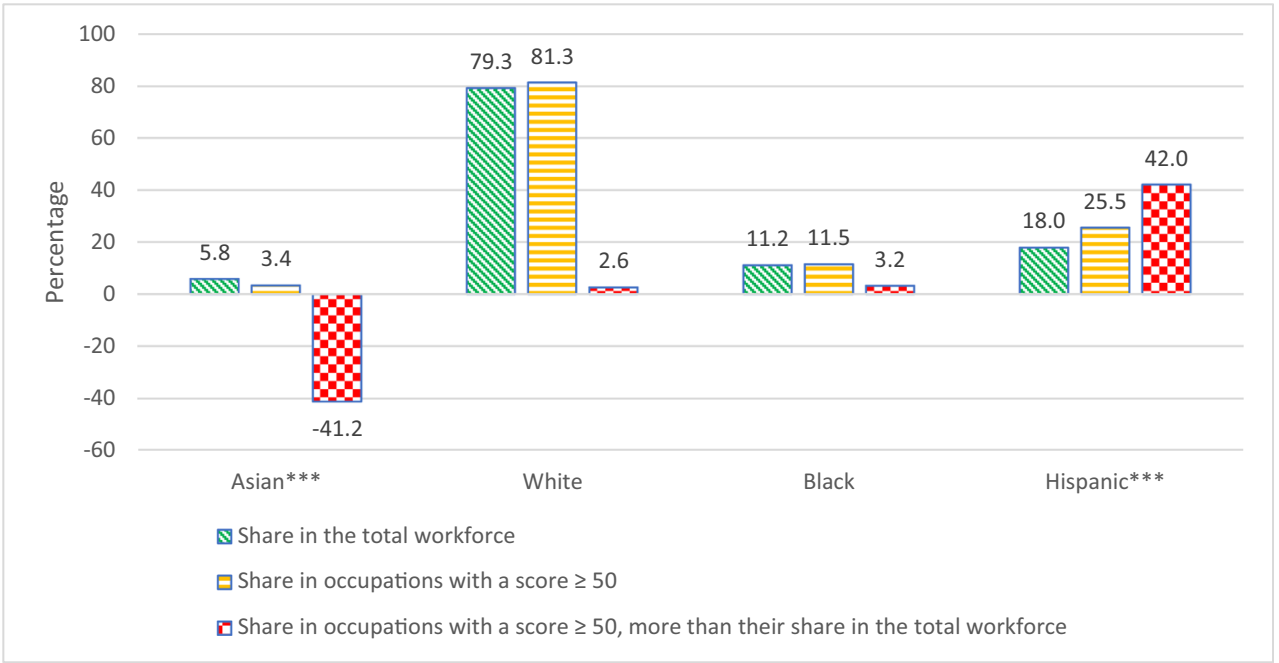


Fig. 9 Mean potential risk for inability to work from home, by occupations in which different racial and ethnic workers were overrepresented relative to their shares in the total workforce. $* * * p<0.01, * * p<0.05$

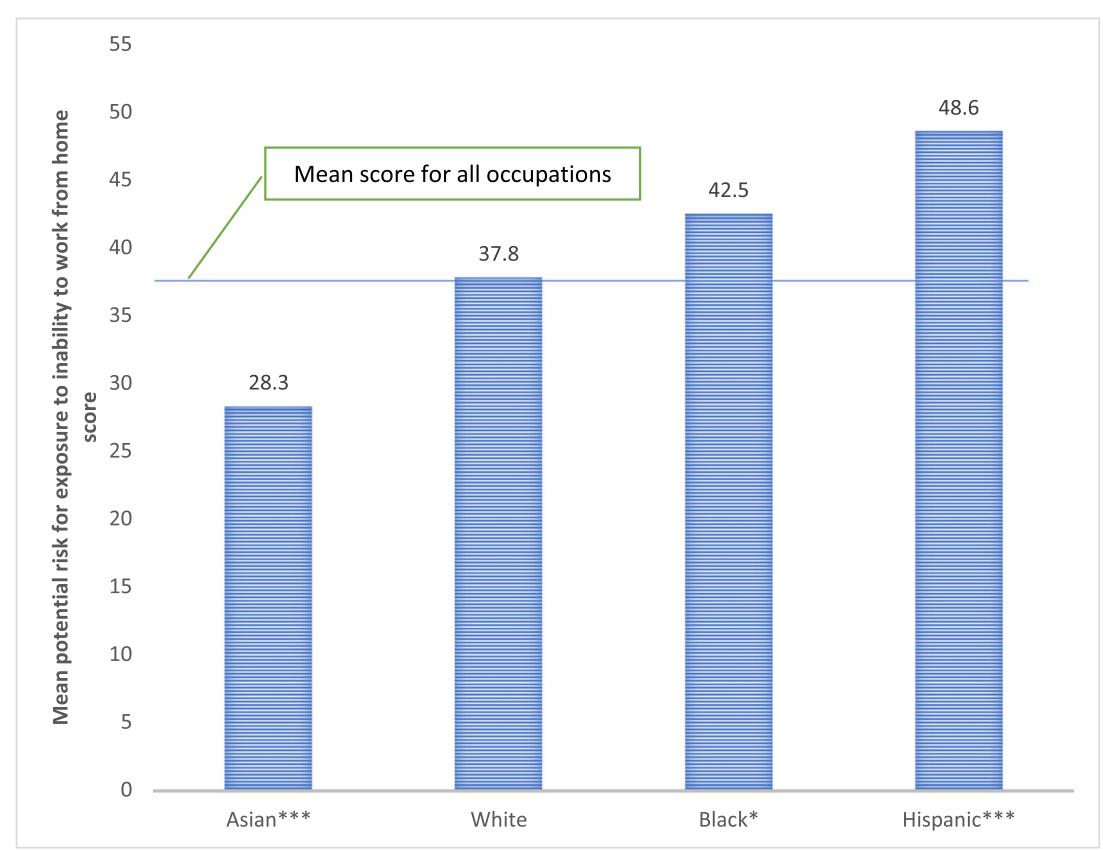

$10 \%$ of the workforce, and I also excluded the "office and administrative support" occupation from the analysis because it has a two-digit SOC code.

The descriptive statistics showed that the share of Black workers in these occupations with high potential risk for exposure to disease or infection at work was $32.6 \%$ higher than their share in the total workforce. In comparison, the share of Hispanic and Asian workers in these occupations was lower than their share in the total workforce. The results also showed that in occupations where Black workers were overrepresented, the mean score for potential risk of exposure to disease and infection at work was $38.3 \%$ higher than the mean score for all occupations. The regression results also showed that in occupations where Black workers were overrepresented, the expected score for potential risk of exposure to disease and infection at work was 2.3 times higher than in occupations where they were underrepresented. Using BLS 2019 employment data, Hawkins [25] found that the percentage of Black or African-American workers employed in occupations with frequent exposure to infections was 31\%,13\%, and 30\% higher than for White, Asian, and Hispanic workers, respectively. The results of this study are not directly comparable to Hawkins' results because whereas Hawkins measured the percentage of different ethnic and racial groups employed in each occupation, I measured the share of different racial and ethnic groups employed in each occupation in relation to their share in the total workforce. I also used more recent data (March and April 2020 instead of 2019) and a different approach to measure the potential exposure risks to COVID-19. Using National Health Interview data, Asfaw [33] also showed that $15.8 \%$ of non-Hispanic Black women volunteered or worked in health care settings, compared with $12.8 \%, 12.3 \%$, and 9.6\% of non-Hispanic Asian women, non-Hispanic White women, and Hispanic women, respectively, during 20162018.

Second, although physical distancing is one of the most important strategies for protecting workers during the pandemic, having the infrastructure necessary to maintain the required physical distancing varies significantly across different occupations. Consequently, some workers may not be able to perform their day-to-day activities while maintaining the required distance between themselves and their co-workers and customers [34, 35]. Availability of space, intensity of work, room temperature, and other related factors affect the ability of workers to maintain physical distancing. In some occupations such as meat processing [36], home health and personal care services, social and community services, and firefighting, there is very limited or no space to implement physical distancing. Moreover, some occupations require frequent physical or face-to-face interactions with customers. Using O*Net data, Leibovici et al. [37] estimated the distribution of contact-intensive occupations by number of hours worked and total labor income. Their results showed that one-fifth of US workers were employed in high-contact-intensity occupations and one-half in medium-contact-intensity occupations. Moreover, workers in some of these occupations may not have access to personal protective equipment (PPE) and proper training on how to use it. Consequently, workers in these occupations might have a higher risk of exposure to infectious diseases such as COVID-19 [15, 38].

The results of this study showed that in the following 10 occupations, the mean score for potential risk of inability to maintain physical distancing was $\geq 50$ : protective service, law 
enforcement, occupational therapy, food preparation and serving, special education teachers, healthcare diagnose or practitioners, health technicians, social workers, protective service, and firefighting and prevention. In these occupations, the share of Asian workers was $31.3 \%$ lower than their share in the total workforce, whereas the share of Black workers was $53.8 \%$ higher than their share in the total workforce. In occupations where Black workers were overrepresented, the mean score for potential risk of inability to maintain physical distancing at work was $11.2 \%$ higher than the mean score for all occupations. Hawkins [25] showed that the percentage of Black or African American workers employed in occupations with frequent close proximity to others was $16 \%, 13 \%$, and $12 \%$ higher than the percentage of White, Asian, and Hispanic workers, respectively. In this study, Asian workers were less likely to be employed in occupations where the score of inability to maintain physical distancing was very high.

Third, in response to COVID-19, some workers were able to perform their job remotely without major problems. The ability of workers to perform their jobs regularly from home varies by occupation. Jobs in some occupations cannot be performed remotely because it is practically impossible to perform the tasks at home. As a result, workers in some occupations are required to report to their workplaces and have little or no option of working remotely [15, 38, 39]. Using the O*Net 'work context' and 'work activities' data, Dingel and Neiman [38] estimated that only $37 \%$ of jobs in the USA can be performed at home. Using the 2018 US BLS employment and $\mathrm{O} *$ Net data, Baker showed that only a quarter of US workers were employed in occupations that could be done from home [40]. Mongey et al. [41] linked the BLS O*Net data with the CPS and Panel Study of Income Dynamics data to identify occupations that could be seriously affected by social distancing. Their results showed that workers with jobs that cannot be performed remotely or that require a high degree of face-to-face interactions are more likely to be vulnerable to economic impacts due to COVID-19. Lu [42] visually presented COVID-19 occupational risks and ability to work from home by mean annual income, using $\mathrm{O} *$ Net data. The study ranked occupations by their COVID-19 risk score and showed that only $9.2 \%$ of workers in the bottom $25 \%$ income percentile can work from home.

The results of this study showed that 29 occupations (out of 83 three-digit level occupations) had scores of $\geq 50$ for potential risk of inability to work from home. Some of these occupations include extraction; construction (helpers and other trades); forest, conservation, and logging; vehicle and mobile equipment (mechanics, installers, and repairers); water transportation; material moving; building cleaning and pest control; metal and plastic woodwork, food processing, and installation (maintenance and repair). More than 33 million workers were employed in these occupations during the study period. Hispanic workers were more exposed to the potential risk of inability to work from home than any other racial and ethnic group. Hispanic workers' share in occupations with scores of $\geq 50$ for potential risk of inability to work from home was $42 \%$ higher than their share in the total workforce. The descriptive analysis showed that in occupations where Hispanic workers were overrepresented the mean potential risk for inability to work from home was $31 \%$ higher than mean score for all occupations. The regression analysis also showed that, in occupations where Hispanic workers were overrepresented, the mean score for potential risk of inability to work from home was more than 1.6 times higher than in occupations where they were underrepresented. Using May 2020-February 2021 CPS data, BLS showed that $41 \%$ of Asian workers teleworked at some point in the last 4 weeks because of the COVID-19 pandemic compared to $21 \%$ of White, $18 \%$ Black, and $14 \%$ Hispanic workers. These results showed that, despite its several limitations [43], the $\mathrm{O} * \mathrm{Net}$ data can be used to study potential occupational risks.

Overall, Black workers were overrepresented in occupations with high potential risk of exposure to disease and infection at work and high potential risk of inability to maintain physical distancing at work, relative to their share in the total workforce. Hispanic workers were overrepresented in occupations where the risk of inability to work from home was high relative to their share in the total workforce. Asian workers, relative to their share in the total workforce, were overrepresented in occupations where the potential risk of inability to work from home was low. All these results showed that Black and Hispanic workers accounted for a disproportionate share of employment in high potential COVID-19 exposure risk occupations, relative to their share in the total workforce; this finding underscores the role occupation might play in the current high infection rate of these groups.

These results supported the recent findings that certain racial and ethnic minority workers were disproportionately employed in occupations with high COVID-19 exposure risks $[17,25]$. Using 2019 BLS employment data, the percentage of different racial and ethnic groups employed in essential industries, and the frequency of exposure to infections and close proximity to others, Hawkins [20] showed that people of color, especially Blacks, were more likely to be employed in industries classified as essential and in occupations with high risk of exposure to infections and close proximity to others. The results also align with the list of essential occupations (health care, funeral services, law enforcement, social workers, teachers, food preparation and serving) identified by CDC as high risk for exposure to COVID-19 at work [44].

The results of this study could have far-reaching implications because these workers are more likely to spread the disease to their racial and ethnic communities [45]. This effect can also be intensified because these racial and ethnic minority groups are more likely to live in poor and crowded neighborhoods and rely on public transportation to go to work and for 
their day-to-day activities $[36,46]$. A recent study showed that non-Hispanic Black and Hispanic children had $30.0 \%$ and $46.4 \%$ higher risk of COVID-19 infection than non-Hispanic White children [47]. Studies have also shown that occupation type is highly correlated with access to paid sick leave and presenteeism [15, 46, 48-50], which are major factors for the spread of influenza-like illness [51].

The results of this study should be interpreted with caution. First, although I used employment data during the pandemic and the O*Net data released in 2020, I did not have information on different measures taken by employers and employees such as installing physical barriers, social distancing, and using PPE in response to the pandemic. For instance, because of the rise of online learning during the COVID-19 pandemic, the risk of infection for schoolteachers would be relatively lower than teaching in person. The unemployment and labor force changes during the first 2 months of the pandemic could impact the percentages employed in different occupations since April 2020, especially given differential impacts of the recession by race and ethnicity [52]. The O*NET data may not also capture job experience for certain racial and ethnic minority groups [53]. Second, CPS does not report racial and ethnic information for occupations that do not meet publication criteria (small number of observations). In the March and April 2020 CPS data, information on race and ethnicity was not reported for over $10 \%$ of the total workforce. However, this would not affect the results of the study in any significant way, as the missing number of workers were almost equally distributed across the four racial and ethnic groups considered in the study. There was less than a one percentage point difference in the share of the four racial and ethnic groups considered in this study compared to the share reported by BLS for the year 2020 aggregated data [44]. Third, I used data aggregated at three-digit level occupations, which might camouflage disparities in the proportion of different racial groups employed in occupations with high potential risk of exposure to COVID-19, such as meat packing, nursing, occupational therapy, and corrections. For instance, in meat packing occupations Hispanic workers constituted $44 \%$ of the total workforce [54]. Fourth, the overrepresentation variable indicates whether the share of each racial and ethnic group in different occupations was higher than its share in the total workforce but does not measure the magnitude of the difference. Finally, I did not control for additional factors such as education, income, and other socioeconomic variables.

\section{Conclusion}

COVID-19 has been claiming the lives of thousands of people in the country and exerting an unacceptably high toll on minority race groups. As of 19 August 2020, Black persons had an 11\% excess risk of dying from COVID-19-related causes, and the proportions of Black and Hispanic persons among total
COVID-19 cases were 1.7 and 1.3 times higher than their proportions in the total population. Understanding risk factors for the disproportionately high impact of COVID-19 on minority groups could help focus efforts to reduce the spread of the disease and narrow the disparity in COVID-19 and other infectious diseaserelated cases, hospitalizations, and mortality.

This study showed that Black and Hispanic workers disproportionately carried the highest potential burden of risk of exposure to COVID-19 at work. Black workers were overrepresented in occupations with high potential risk of exposure to disease and infection at work and inability to maintain physical distancing at work, and Hispanic workers were overrepresented in occupations with high risk of inability to work from home relative to their share in the total workforce, indicating that occupation can be a risk factor for the disproportionate impact of COVID-19 on these minority groups. This knowledge can be useful in devising targeted prevention interventions in high risk occupations, including educational programs, providing adequate PPE, training, working space, and vaccination to reduce the spread of COVID-19 and its disproportionately high impact on certain minority ethnic and racial groups. Future research might also explore exposure risks of different occupations by using data after COVID19 and occupations at an eight-digit SOC level.

Acknowledgements The author thanks Regina Pana-Cryan (CDCNIOSH), Brian Quay (CDC-NIOSH), Leslie Boden (Boston University), and Roger Rosa (CDC-NIOSH) for their helpful comments and suggestions on earlier version of the paper. He also thanks Seleen Collins for her excellent editorial service.

Funding No external funding was provided for this research. The author declares no actual or potential conflicts of interest.

Availability of Data and Materials The data used in this study are publicly available at https://data.census.gov/mdat/\#/ and https://www. onetcenter.org/database.html\#individual-files.

Code Availability Stata codes used in this study are available from the author upon request.

Declarations The findings and conclusions in this paper are those of the author and do not necessarily represent the views of the National Institute for Occupational Safety and Health.

Conflicts of Interest The author, Asfaw, declares that he has no conflict of interest.

\section{References}

1. Centers for Disease Control and Prevention (CDC). COVID data tracker: demographic trends of COVID-19 cases and deaths in the US reported to CDC. Accessed June 20, 2021.

2. The COVID Tracking Project. The COVID Racial Data Tracker: COVID-19 is affecting Black, Indigenous, Latinx, and other people of color the most. https://covidtracking.com/race Accessed Mar 24, 2021. 
3. Yancy CW. COVID-19 and African Americans. Jama, 2020.

4. van Dorn A, Cooney RE, Sabin ML. COVID-19 exacerbating inequalities in the US. Lancet (London, England). 2020;395(10232): 1243.

5. Cockerham WC, Hamby BW, Oates GR. The social determinants of chronic disease. 2017. Elsevier.

6. Fothergill A, Peek LA. Poverty and disasters in the United States: a review of recent sociological findings. Nat Hazards. 2004;32(1): 89-110.

7. Kristal T, Cohen Y, Navot E. Benefit inequality among American workers by gender, race, and ethnicity, 1982-2015. Sociol Sci. 2018;5:461-88.

8. Quiñones AR, Botoseneanu A, Markwardt S, Nagel CL, Newsom JT, Dorr DA, et al. Racial/ethnic differences in multimorbidity development and chronic disease accumulation for middle-aged adults. PLoS One. 2019;14(6):e0218462.

9. Laurencin CT, McClinton A. The COVID-19 pandemic: a call to action to identify and address racial and ethnic disparities. J Racial Ethn Health Disparities. 2020;7(3):398-402.

10. Graham $\mathrm{G}$, Addressing the disproportionate impact of COVID-19 on communities of color. J Racial Ethn Health Disparities, 2021: p. $1-3$.

11. Gould EL, Rawlston-Wilson V. Black workers face two of the most lethal preexisting conditions for coronavirus-racism and economic inequality: Report. 2020: Economic Policy Institute.

12. Centers for Disease Control and Prevention (CDC). Proportion of people tested for SARS-CoV-2 (COVID-19) who had a positive test result. https://www.cdc.gov/coronavirus/2019-ncov/ community/health-equity/racial-ethnic-disparities/increased-riskillness.html Accessed Mar 29, 2021.

13. Kurgat EK, Sexton JD, Garavito F, Reynolds A, Contreras RD, Gerba CP, et al. Impact of a hygiene intervention on virus spread in an office building. Int J Hyg Environ Health. 2019;222(3):47985 .

14. Danovaro-Holliday MC, LeBaron C, Allensworth C, Raymond R, Borden TG, Murray AB, et al. A large rubella outbreak with spread from the workplace to the community. Jama. 2000;284(21):27339.

15. Baker MG, Peckham TK, Seixas NS. Estimating the burden of United States workers exposed to infection or disease: a key factor in containing risk of COVID-19 infection. PLoS One. 2020;15(4): e0232452.

16. Koh D. Occupational risks for COVID-19 infection. Occupational medicine (Oxford, England). 2020;70(1):3.

17. McClure ES, Vasudevan P, Bailey Z, Patel S, Robinson WR. Racial capitalism within public health: how occupational settings drive COVID-19 disparities. Am J Epidemiol. 2020;189:1244-53.

18. Krieger N. Epidemiology and the people's health: theory and context. 2011: Oxford University Press.

19. Marrett CB. Racial disparities and COVID-19: the social context. Journal of Racial and Ethnic Health Disparities, 2021: p. 1-4.

20. Ford TN, Reber S, Reeves RV. Race gaps in COVID-19 deaths are even bigger than they appear. https://www.brookings.edu/blog/upfront/2020/06/16/race-gaps-in-covid-19-deaths-are-even-biggerthan-they-appear/. Accessed 22 Mar 2020.

21. Hughes MM, Groenewold MR, Lessem SE, Xu K, Ussery EN, Wiegand RE, et al. Update: characteristics of health care personnel with COVID-19-United States, February 12-July 16, 2020. Morb Mortal Wkly Rep. 2020;69(38):1364-8.

22. Hawkins D. Social determinants of COVID-19 in Massachusetts, United States: an ecological study. J Prev Med Public Health. 2020;53(4):220-7.

23. McLaren, J. Racial disparity in COVID-19 deaths: seeking economic roots with census data, National Bureau of Economic Research. 2020.
24. Arasteh K. Prevalence of comorbidities and risks associated with COVID-19 among Black and Hispanic populations in New York City: an examination of the 2018 New York City Community Health Survey. J Racial Ethn Health Disparities. 2020(p):1-7.

25. Hawkins D. Differential occupational risk for COVID-19 and other infection exposure according to race and ethnicity. Am J Ind Med. 2020;63:817-20.

26. Schuchat, A. Public health response to the initiation and spread of pandemic COVID-19 in the United States, February 24-April 21, 2020. MMWR. Morbidity and mortality weekly report, 2020. 69.

27. Bureau of Labor Statistics (BLS). Standard occupational classification. https://www.bls.gov/soc/ Accessed July 21, 2021.

28. Bureau of Labor Statistics (BLS). Employed persons by detailed occupation, sex, race, and Hispanic or Latino ethnicity. https:// www.bls.gov/cps/cpsaat11.htm Accessed July 21, 2021.

29. Centers for Disease Control and Prevention (CDC). COVID-19 in racial and ethnic minority groups. Coronavirus Disease 2019 (COVID-19) https://www.cdc.gov/coronavirus/2019-ncov/needextra-precautions/racial-ethnic-minorities.html Accessed August 22, 2020.

30. Bhala N, Curry G, Martineau AR, Agyemang C, Bhopal R. Sharpening the global focus on ethnicity and race in the time of COVID-19. Lancet. 2020;395(10238):1673-6.

31. Chowkwanyun M, Reed AL Jr. Racial health disparities and Covid19 - caution and context. N Engl J Med. 2020;383:201-3.

32. Occupational Safety and Health Adminstration (OSHA). Healthcare: Infectious diseases. https://www.osha.gov/healthcare/ infectious-diseases Accessed June 21, 2021.

33. Asfaw A. Percentage of adults who volunteered or worked in a hospital, medical clinic, doctor's office, dentist's office, nursing home, or some other health care facility, by sex, race, and hispanic origin-national health interview survey, United States, 2016-2018. MMWR Morb Mortal Wkly Rep. 2020;69(28):941.

34. Avdiu B. Nayyar G. When face-to-face interactions become an occupational hazard: Jobs in the time of COVID-19. 2020, The World Bank.

35. Jarvis CI, et al. Quantifying the impact of physical distance measures on the transmission of COVID-19 in the UK. BMC Med. 2020;18:1-10.

36. Dyal JW, et al. COVID-19 among workers in meat and poultry processing facilities-19 states, April 2020. MMWR. Morbidity and mortality weekly report, 2020.69.

37. Leibovici F, Santacreu AM, Famiglietti M. Social distancing and contact-intensive occupations. St. Louis FED: On the economy; 2020.

38. Dingel JI, Neiman B. How many jobs can be done at home? 2020, National Bureau of Economic Research.

39. Webster R, et al. A systematic review of infectious illness presenteeism: prevalence, reasons and risk factors. BMC Public Health. 2019;19(1):799.

40. Baker MG. Nonrelocatable occupations at increased risk during pandemics: United States, 2018. Am J Public Health. 2020;110(8):1126-32.

41. Mongey S, Pilossoph L, Weinberg A. Which workers bear the burden of social distancing policies? 2020, National Bureau of Economic Research.

42. $\mathrm{Lu} \mathrm{M}$. The front line: Visualizing the occupations with the highest COVID-19 risk. https://www.visualcapitalist.com/the-front-linevisualizing-the-occupations-with-the-highest-covid-19-risk/. Accessed 7/30/2020, 2020.

43. Handel MJ. The $\mathrm{O} *$ NET content model: strengths and limitations. Journal for Labour Market Research. 2016;49(2):157-76.

44. Centers for Disease Control and Prevention (CDC). Interim list of categories of essential workers mapped to standardized industry codes and titles. https://www.cdc.gov/vaccines/covid-19/ categories-essential-workers.html Accessed June 20, 2021. 
45. Granovetter MS. The strength of weak ties, in Social networks. 1977, Elsevier. p. 347-367.

46. Bryan AD-GJ, Davis N, Chokshi D, Galea S. Moving from the five whys to five hows: addressing racial inequities in COVID-19 infection and death, in Health Affairs Blog. 2020, Health Affairs: Washington, DC.

47. Goyal MK, Simpson JN, Boyle MD, Badolato GM, Delaney M, McCarter R, et al. Racial/ethnic and socioeconomic disparities of SARS-CoV-2 infection among children. Pediatrics. 2020;146: e2020009951.

48. O'Connor R, Hayes J, Gault B. Paid sick days access varies by race/ethnicity, sexual orientation, and job characteristics. Inst Women's Policy Res, 2014. 337.

49. DeRigne L, Stoddard-Dare P, Collins C, Quinn L. Paid sick leave and preventive health care service use among US working adults. Prev Med. 2017;99:58-62.

50. Asfaw A, Rosa R, Pana-Cryan R. Potential economic benefits of paid sick leave in reducing absenteeism related to the spread of influenza-like illness. J Occup Environ Med. 2017;59(9):822-9.
51. Pouliakas K, Branka J. EU jobs at highest risk of COVID-19 social distancing: will the pandemic exacerbate labour market divide? 2020.

52. Gezici A, Ozay O. How race and gender shape covid-19 unemployment probability. Available at SSRN 3675022, 2020.

53. Fujishiro K, Koessler F. Comparing self-reported and O* NETbased assessments of job control as predictors of self-rated health for non-Hispanic whites and racial/ethnic minorities. PLoS One. 2020;15(8):e 0237026.

54. Center for Economic and Policy Research (CEPR). Meatpacking workers are a diverse group who need better protections. https:// www.bls.gov/cps/cpsaat11.htm Accessed June 21, 2021.

Publisher's Note Springer Nature remains neutral with regard to jurisdictional claims in published maps and institutional affiliations. 